\title{
SARKASME PADA MEDIA SOSIAL TWITTER DAN IMPLIKASINYA TERHADAP PEMBELAJARAN BAHASA INDONEISIA DI SMA
}

\author{
Siska Lutfiyani ${ }^{1}$, Burhan Eko Purwanto ${ }^{2}$, Syamsul Anwar ${ }^{3}$ \\ Universitas Pancasakti Tegal \\ Pos-el: Siskalutfi187@gmail.com ${ }^{1}$,burhanekopurwanto58@gmail.com², \\ syamsulanwar590@gmail.com ${ }^{3}$
}

Diserahkan: 22 Juli 2020, Direvisi: 25 November 2020, Diterima: 11 Februari 2021

\begin{abstract}
This research is a sarcasm on Twitter social media. The purpose of this study is to describe the form of sarcasm on Twitter social media and to describe the implications of learning Indonesian in high school. The approach used in this research is to use a qualitative approach, the method used is the equivalent method. The data is obtained by reading the social media account comments column @fadlizon then recording words and sentences containing the style of sarcasm and analyzed. The results of this study use the Elizabeth Camp theory there are 4 types of sarcasm, namely designation sarcasm, lexical sarcasm, sarcasm and illocutionary sarcasm by finding 24 data and then implicated in Indonesian language learning in high school class X semester II curriculum 2013.
\end{abstract}

Keywords: Sarcasm, twitter, Indonesian language learning. 


\begin{abstract}
Abstrak
Penelitian ini merupakan sarkasme pada media sosial twitter. Tujuan penelitian ini yaitu untuk mendeskripsi wujud sarkasme pada media sosial twitter dan mendeskripsi implikasi pembelajaran Bahasa Indonesia di SMA. Pendekatan yang digunakan pada penelitian ini yaitu menggunakan pendekatan kualitatif, metode yang digunakan adalah metode padan. Data diperoleh dengan membaca kolom komentar akun media sosial twitter@fadlizon kemudian mencatat kata dan kalimat yang mengandung gaya bahasa sarkasme dan dianalisis. Hasil penelitian ini menggunakan teori Elizabeth Camp terdapat 4 jenis sarkasme yaitu sarkasme sebutan, sarkasme leksikal, sarkasme sifat dan sarkasme ilokusi dengan menemukan 24 data kemudian diimplikasikan pada pembelajaran Bahasa Indonesia di SMA kelas X semester II kurikulum 2013.
\end{abstract}

Kata Kunci: Sarkasme, Twitter, Pembelajaran Bahasa Indonesia.

\title{
PENDAHULUAN
}

Manusia sebagai makhluk sosial tentu tidak akan lepas dari bahasa, baik bahasa lisan maupun bahasa tulis. Bahasa digunakan sebagai alat komunikasi sehari-hari untuk mengungkapkan ide, pikiran, gagasan dalam menyampaikan informasi dan pendapat (Restivayani, 2010:1). Bahasa adalah alat komunikasi yang disampaikan kepada orang lain berupa bunyi dan memiliki makna. Bahasa juga bisa disebut sebagai kebudayaan dan tidak dapat dipisahkan dengan masyarakat sebagai penggunanya. Ia dapat tumbuh dan berkembang jika digunakan oleh masyarakat. Begitupun sebaliknya, bahasa akan punah jika tidak digunakan oleh masyarakat. Pada dasarnya keduanya saling berkaitan, karena manusia tidak akan mampu beraktivitas tanpa bahasa (Hermaji, 2016: 2).

Perkembangan bahasa dipengaruhi oleh teknologi informasi dan komunikasi yang canggih, seperti gawai. Gawai merupakan alat komunikasi yang mudah digunakan. Pemanfaatan media 
sosial sekarang membuat pengguna menjadi ketergantungan yang memberikan dampak positif dan negatif. Misalnya, pada situs jejaring sosial twitter. Pengguna twitter dapat memunculkan bahasa sarkasme yang menyebabkan pelanggaran prinsip kesantunan berbahasa.

Peneliti memilih akun media sosial twitter karena selain untuk memenuhi kebutuhan penelitian, juga penelitian terkait gaya bahasa sarkasme pada akun media sosial twitter belum banyak dilakukan. Akun twitter yang dipilih adalah @fadlizon. Analisis dilakukan dengan tahap membaca kolom komentar akun twitter@ fadlizon yang mengandung gaya bahasa sarkasme.

Berdasarkan pemaparan tersebut penelitian ini bertujuan untuk menganalisis gaya bahasa sarkasme pada kolom komentar akun media sosial twitter @fadlizon dan implikasinya terhadap pembelajaran Bahasa Indonesia di SMA.

\section{KAJIAN LITERATUR}

Penelitian ini memerlukan beberapa teori untuk memperkuat temuan-temuan di lapangan agar mendapatkan data yang lebih akurat. Teori tersebut antara lain, pragmatik, sarkasme, Elizabeth Camp, media sosial, dan pembelajaran Bahasa Indonesia di SMA.

Pragmatik adalah ilmu bahasa yang mempelajari makna berdasarkan konteks penggunaannya. Pragmatik merupakan ilmu bahasa yang mengkaji makna dengan pertimbangan konteks. Dengan demikian, makna yang dikaji dalam pragmatik tidak bisa dipisahkan dengan konteks yang melingkupinya. Konteks merupakan hal terpenting dalam kajian pragmatik. Artinya, pragmatik merupakan bidang ilmu bahasa yang mengkaji fungsi dan maksud tuturan atau ujaran (Hermaji, 2016: 15).

Sarkasme merupakan suatu acuan yang lebih kasar dari ironi dan sinisme. Ia adalah suatu acuan yang mengandung kepahitan dan celaan yang getir. Contohnya, Lihat sang raksasa itu (maksudnya si cebol) dan Mulut kau harimau kau. Sarkasme dapat saja bersifat ironis, dapat juga tidak, tetapi yang jelas adalah bahwa gaya bahasa ini selalu akan menyakiti hati dan kurang enak didengar. Kata sarkasme 
diturunkan dari kata Yunani sarkasme yang lebih jauh diturunkan dari kata kerja sakasein yang berarti "merobek-robek daging seperti anjing", "menggigit bibir karena marah", atau "berbicara dengan kepahitan" (Keraf, 2009:143-144). Sarkasme mempunyai ciri utama yaitu mengandung kepahitan dan celaan yang getir, kurang enak didengar dan menyakiti hati.

Secara umum media sosial adalah media online yang digunakan untuk berkomunikasi. Kehadiran media sosial menimbulkan dampak tersendiri bagi masyarakat, misalnya memudahkan untuk berkomunikasi dalam jarak jauh secara cepat sebagai wadah untuk berinteraksi dan bersosialisasi. Luasnya jaringan manusia bisa berkomunukasi dengan mudah kapanpun dimanapun secara mudah, praktis, dan cepat (Inderasari, 2019 :2).

Twitter adalah salah satu situs jejaring sosial yang mudah digunakan untuk berkomunikasi, mendapatkan infomasi yang berupa status, gambar dan video. Dengan adanya media sosial semua orang bisa menggunakannya kapanpun dan dimanapun. Pada twitter semua orang bisa mendapatkan informasi dan berkomunikasi dari pengguna lainnya, dan juga bisa berargumentasi secara bebas.

Sebelum penelitian ini di lakukan lebih lanjut, peneliti dapat melakukan perbandingan antara peneliti yang sedang diteliti dengan penelitian terdahulu yang memiliki pokok permasalahan yang mirip atau objek kajian yang sama, perbandingan ini dilakukan agar peneliti tidak dianggap mengutip peneliti sebelumnya.

Mahmudah dalam Jurnal Retorika Bahasa Sastra dan Pengajarannya dengan judul penlitian Sarkasme Judul Berita Surat Kabar Nasional. Hasil penelitian menunjukkan bahwa penggunaan bahasa sarkasme melanggar prinsip-prinsip sopan santun (Mahmudah, 2012). Persamaan penelitian ini yaitu terletak pada penelitian yang berupa kata dan kalimat, perbedaannya terletak pada teknik dan objeknya. Teknik yang digunakan pada penelitian ini yaitu menggunakan teknik catat dan memilih judul berita surat kabar nasional sebagai objeknya, sedangkan pada penelitian yang 
sedang dilakukan menggunakan teknik baca, teknik catat, dan memilih objek media sosial twitter.

Selanjutnya penelitian yang dimuat dalam International Journal of Humor Research dengan judul penelitian On Sarcasm, Sosial Awareness, and Gender. Hasil penelitian menunjukkan bahwa sarkasme adalah jenis humor yang agresif membandingkan jenis kelamin (Mary, 2015). Persamaan pada penelitian ini terletak pada pendekatan kualitatif, perbedaannya terletak pada peneliti ini menggunakan metode padan dan agih sedang penelitian yang sedang dilakukan menggunakan metode padan.

Heru dalam Jurnal Pembelajaran Bahasa dan Sastra Indonesia dengan judul penlitian Gaya Bahasa Sindiran Ironi, Sinisme dan Sarkasme dalam Berita Utama Harian Kompas. Hasil penelitian menunjukan bahwa penggunaan gaya bahasa sindiran sarkasme melanggar prinsip sopan santun yang meliputi maksim kearifan, maksim kedermawanan, maksim kesepakatan, dan maksim simpati. Persamaan penelitian ini yaitu terletak pada penelitian yang berupa kata dan kalimat, perbedaannya terletak pada teknik yang digunakan, peneliti ini menggunakan teknik dokumentasi dan teknik catat (Heru, 2018). Sedangkan penelitian yang sedang dilakukan menggunakan teknik baca dan catat.

\section{METODE PENELITIAN}

Pendekatan yang digunakan pada penelitian ini ialah pendekatan kualitatif, karena penelitian ini menganalisis gaya bahasa sarkasme pada media sosial twitter. Sumber data pada penelitian ini yaitu akun media sosial twitter@fadlizon. Wujud data berupa kata dan kalimat sarkasme pada kolom komentar akun media sosial twitter@fadlizon. Identifikasi data pada penelitian ini yaitu dengan mencari kata atau kalimat yang mengandung majas sarkasme dalam kolom komentar akun media sosial twitter@fadlizon kemudian mengumpulkan, menganalisis, dan mendata hasil analisis. Teknik pengumpulan data menggunakan metode baca dan catat. Peneliti membaca kolom komentar pada media sosial twitter, kemudian 
yang mencatat gaya bahasa sarkasme yang terdapat pada kolom komentar akun media sosial twitter @fadlizon. Teknik analisis data yang digunakan pada penelitian ini yaitu dengan menggunakan metode padan. Metode padan adalah metode analisis data yang alat penentunya berada di luar bahasa. Dalam penelitian ini data yang akan di analisis adalah sarkasme pada media sosial twitter@fadlizon dan teknik penyajian hasil analisis menggunakan teknik informal.

\section{HASIL PENELITIAN DAN PEMBAHASAN}

Analisis dilakukan dengan tahap membaca kolom komentar akuntwitter@fadlizon yang mengandung gaya bahasa sarkasme. Dari hasil analisis tersebut analisis menemukan 4 jenis sarkasme yaitu sarkasme sebutan, sarkasme leksikal, sarkasme sifat, dan sarkasme ilokusi.

\section{Sarkasme Sebutan}

Berdasarkan analisis ditemukan 7 data sarkasme sebutan yaitu.

\section{Data 1}

@pasmantab “ga jujurnya dimana jing?” (Twitter @fadlizon diunggah pada tanggal 22 Februari 2020).

Penanda sarkasme sebutan pada kolom komentar akun twitter @fadlizon ini dapat ditemukan pada kalimat "ga jujurnya dimana jing?" "jing” di sini maksudnya yaitu anjing, anjing dalam KBBI memiliki makna binatang menyusui yang biasa dipelihara untuk menjaga rumah, berburu, dan sebagainnya. Netizen menyamakan Fadli Zon seperti anjing.

\section{Data 2}

@Adenyoikow "sekali-kali kau kritik si prabowo nyeett..!! brani ggak loe zonkk..?! mulut comberan sampah kaya kau ini kritik kok milih2! di sumpal taeik kuda si wowo baru tau kau bangsat..!!” (Twitter @ fadlizon diunggah pada tanggal 23 Februari 2020).

Penanda sarkasme sebutan pada kolom komentar akun twitter@fadlizon ini dapat ditemukan pada kalimat "sekali-kali kau 
kritik si prabowo nyeett..!! brani ggak loe zonkk..?! mulut comberan sampah kaya kau ini kritik kok milih2 ! di sumpal taeik kuda si wowo baru tau kau bangsat..!! "nyet" yang dimaksud adalah monyet, "comberan" dalam KBBI artinya selokan (lubang) pembuangan air kotor, pelimbahan, got. "sampah" artinya barang atau benda yang dibuang karena tidak terpakai lagi. Kata "bangsat" dalam KBBI artinya orang yang bertabiat jahat (terutama yang suka mencuri dan mencopet). Pada komentar ini dimaksudkan netizen menyamakan Fadli Zon dengan hewan monyet, "mulut comberan sampah" apa yang dibicarakan Fadli Zon semuanya tidak ada yang benar, busuk bagaikan sampah.

\section{Data 3}

@Mustaqimsuyati "masuk dua periode kau jadi anggota dewan tapi mulutmu tetap kayak comberan tidak berguna bagi rakyat Indonesia." (Twitter@fadlizon diunggah pada tanggal 24 Januari 2020).

Penanda sarkasme sebutan pada kolom komentar akun twitter@fadlizon ini dapat ditemukan kata "comberan". "comberan" dalam KBBI memiliki arti selokan (lubang) pembuangan air kotor, pelimbahan. Dapat disimpulkam dari komentar tersebut bahwa netizen melihat @fadlizon masuk dua periode menjadi anggota dewan tetapi mulutnya bagaikan comberan, busuk. Semua perkataan Fadli Zon tidak berguna bagi rakyat Indonesia.

\section{Data 4}

@Tukangmu "kamu mengingatkanku pada receh gopean. Bermuka dua dan nggak terlalu berharga." (Twitter @fadlizon diunggah pada tanggal 19 Februari 2020).

Penanda sarkasme sebutan pada kolom komentar akun twitter @fadlzon ini dapat ditemukan kalimat "Kamu mengingatkanku pada receh gopean. Bermuka dua dan tidak terlalu berharga". Dalam komentar tersebut terdapat kalimat "kamu mengingatkanku pada receh gopean yang bermuka dua dan tidak terlalu berharga" menggambarkan sifat seseorang bermuka dua yang di depan terlihat baik tetapi di belakang menjelek-jelekan, dan disamakan seperti 
receh gopean tidak terlalu berharga. Orang yang memiliki sifat bermuka dua dianggap tidak berharga.

\section{Data 5}

@andri_att “diaam kau buntelan kentut." (Twitter @fadlizon diunggah pada tanggal 1 April 2020). Penanda sarkasme sebutan pada kolom komentar akun twitter@fadlizon ini dapat ditemukan kalimat "diam kau buntelan kentut".

Dalam komentar tersebut netizen menyamaan Fadli Zon dengan buntelan kentut. "buntel" dalam KBBI memiliki arti bungkusan, "kentut" memiliki arti gas berbau busuk (gas busuk) yang keluar dari anus. Hal ini menggambarkan sifat dan perilaku seseorang yang mempunyai niatan tidak baik.

\section{Sarkasme Leksikal}

\section{Data 6}

@bg_husin “kamu jadi anggota dewan pakai otak gak?”(Twitter@ fadlizon diunggah pada tanggal 21 Januari 2020).

Penanda sarkasme leksikal pada kolom komentar akun twitter@fadlizon ini dapat ditemukan pada kalimat "kamu jadi anggota dewan pakai otak gak". Dalam komentar tersebut netizen menyindir Fadli Zon bahwa selama jadi anggota dewan Fadli Zon seperti tidak memakai otak, atau seenaknya sendiri.

\section{Data 7}

@BB97732112 "mulut anggota dewan ternyata kaya comberan kalo mbacot yaa? Keliatan cerdas tapi kosong otakmu zon.. kau sadar gak, subsidi utk siapa? mellek gak matamu siapa aja yang pake gas $3 \mathrm{~kg}$ itu? Coba kalo kepalamu ada otaknya, dicerna hal sedemikian itu." (Twitter@fadlizon diunggah pada tanggal 21 Januari 2020).

Kata "comberan" dalam KBBI memiliki arti pembuangan air kotor, pelimbahan, got. Dalam komentar tersebut netizen menyebutkan bahwa mulut seorang anggota dewan ternyata seperti comberan kalo berbicara, terlihat cerdas, namun pada kenyataannya kosong, tidak digunakan dengan baik. 


\section{Data 8}

@iimsuryawiguna “jijik banget ngeliatnya..pengen muntah." (Twitter@fadlizon diunggah pada tanggal 25 Mei 2020).

Kata "jijik" dalam KBBI memiliki arti tidak suka melihat (merasa mual) karena kotor, keji”. Dalam komentar tersebut netizen jelas mengungkapkan rasa tidak sukanya terhadap Fadli Zon bahwa ketika melihat muka Fadli zon merasakan mual ingin muntah.

\section{Data 9}

@Imus28 “Terlihat polos kedungu-dunguan.” (Twitter @fadlizon diunggah pada tanggal 15 April 2020).

Penanda sarkasme leksikal pada kolom komentar akun twitter @fadlizon ini dapat ditemukan kalimat "Terlihat polos kedungudunguan". Kata "dungu " dalam KBBI memiliki arti sangat tumpul otaknya, tidak cerdas, bebal bodoh, "kedunguan" memiliki arti kebodohan, kebebalan. Dalam komentar tersebut dapat disimpulkan bahwa walaupun telihat polos tapi sebenarnya bodoh kebodohan.

\section{Sarkasme Sifat}

\section{Data 10}

@Gasperszidha "si zonk, demi nyinyir terlihat bodoh dan dungu." (Twitter@fadlizon diunggah pada tanggal 12 Januari 2020).

Penanda sarkasme sifat pada kolom komentar akun twitter @fadlizon ini dapat ditemukan pada kalimat "si zonk, demi nyinyir terlihat bodoh dan dungu". "nyinyir" dalam KBBI yaitu mengulangulang perintah atau permintaan, nyenyeh, cerewet. "bodoh" dalam KBBI memiliki arti tidak memiliki (pengetahuan atau pengalaman). "dungu" dalam KBBI memiliki arti sangat tumpul otaknya, tidak cerdas, bebal, bodoh. Maksud pada komentar disini yaitu netizen melihat Fadli Zon ketika berbicara terlihat bodoh.

\section{Data 11}

@Gorgogo07 “Dia tertular goblok dari bos nya.” (Twitter @fadlizon diunggah pada tanggal 1 April 2020). 
Penanda sarkasme sifat pada kolom komentar akun twitter@ fadlizon ini dapat ditemukan pada kalimat "Dia tertular goblok dari bos nya." "Goblok" memiliki arti bodoh atau tidak pintar. Dalam komentar tersebut dapat disimpulkan netizen mengatakan bahwa Fadli Zon tertular goblok dari bosnya, dianggap bodoh atau tidak pintar.

\section{Data 12}

@Dwisetiawan “sombong” (Twitter @fadlizon diunggah pada tanggal 25 Januari 2020).

Penanda sarkasme sifat pada kolom komentar akun twitter@ fadlizon ini dapat ditemukan pada kata "sombong", kata "sombong" dalam KBBI memiliki arti menghargai diri secara berlebihan. Hal ini membuat netizen atau orang yang membenci Fadli Zon semangkin menganggap dia memang sombong.

\section{Data 13}

@Jay_Riesman66 “maaf @fadlizon anda terlalu OGEB.”(Twitter @ fadlizon diunggah pada tanggal 31 Maret 2020).

Penanda sarkasme sifat pada kolom komentar akun twitter @fadlizon ini dapat berupa kalimat "maaf @fadlizon anda terlalu OGEB", "OGEB" maksudnya BEGO. Bego dalam KBBI memiliki makna sangat bodoh.

\section{Data 14}

@PujiantoHary “otak fadli makin soak setelah @prabowo jadi pembantu @jokowi.” (Twitter @fadlizon diunggah pada tanggal 21 Januari 2020).

Penanda sarkasme sifat pada kolom komentar akun twitter @fadlizon ini dapat ditemukan pada kalimat "otak fadli makin soak setelah@prabowo jadi pembantu @jokowi”. “soak” dalam KBBI memiliki arti lemah, tidak kuat lagi (tentang baterai dan sebagainya) baterai lampu senternya sudah soak dalam artian sudah tidak berfungsi lagi tidak berguna. Fadli Zon disamakan seperti baterai soak yang sudah tidak berguna lagi. 


\section{Data 15}

@Kallem "Seharusnya anda tidak bicara di sosmed. Itu pertanda anda bodoh.. bisa dipahami?" (Twitter @fadlizon diunggah pada tanggal 25 Januari 2020).

Penanda sarkasme sifat pada kolom komentar akun twitter@ fadlizon ini dapat ditemukan kalimat "seharusnya anda tidak bicara di sosmed. Itu pertanda anda bodoh". "bodoh" dalam KBBI memiliki arti tidak memiliki (pengetahuan atau pengalaman).

\section{Data 16}

@celeb8900 “goblok." (Twitter @fadlizon diunggah pada tanggal 18 Februari 2020).

Penanda sarkasme sifat pada kolom komentar akun media sosial twitter@fadlizon ditemukan kata "goblok". "Goblok" dalam KBBI memiliki arti bodoh atau tidak pintar. Pada komentar tersebut netizen mengatakan bahwa Fadli Zon memiliki sifat bodoh atau tidak pintar.

\section{Data 17}

@mazbagusjogja “gemblung.” (Twitter @fadlizon diunggah pada tanggal 1 April 2020).

Penanda sarkasme sifat pada kolom komentar akun media sosial twitter @fadlizon ditemukan kata "gemblung". "gemblung" dalam KBBI memiliki arti setengah gila, bandel, bodoh. Netizen menganggap bahwa Fadli Zon gila.

\section{Data 18}

@RiniNurB “iya bukannya beri solusi, ini malah nyinyir”. (Twitter@ fadlizon diunggah pada tanggal 1 April 2020).

Penanda sarkasme sifat pada kolom komentar akun media sosial twitter@fadlizon ditemukan kalimat "iya bukannya beri solusi, ini malah nyinyir". "nyinyir" dalam KBBI memiliki arti mengulangulang perintah atau permintaan, nyenyeh, cerewet.".Dalam komentar tersebut netizen melihat bahwa Fadli Zon ketika ada masalah 
bukannya memberikan solusi terbaiknya sebagai wakil rakyat malah banyak ngomong yang tidak penting.

\section{Sarkasme Ilokusi}

\section{Data 19}

@Regar971 “Bacot mulu kau bangsat fuck.” (Twitter @fadlizon diunggah pada tanggal 24 Januari 2020).

Penanda sarkasme ilokusi pada kolom komentar akun twitter @fadlizon ini dapat ditemukan kata "bangsat" dalam KBBI memiliki arti gembel miskin. Dalam komentar tersebut maksudnya adalah Fadli Zon diibaratkan seperti gembel yang banyak omong.

\section{Data 20}

@Wildan_batarfie “Zonk bacooooot.” (Twitter @fadlizon diunggah pada tanggal 12 Februari 2020).

Penanda sarasme ilokusi pada kolom komentar akun twitter @fadlizon ini dapat ditemukan kata "bacot" dalam KBBI memili arti mulut. Dalam komentar tersebut dapat disimpulkan bahwa kata "zoonk bacoot" memiliki makna Fadli Zon banyak omong.

\section{Data 21}

@firman16021 "Maklum iblis berbentuk manusia." (Twitter @ fadlizon diunggah pada tanggal 1 April 2020).

Dalam komentar tersebut maksudnya adalah netizen menyamakan Fadli Zon seperti manusia yang memiliki sifat seperti iblis atau bisa juga disebut jahat.

\section{Data 22}

@Dianafithras “Fadli Zon adalah SAMPAH yang tidak bisa didaur ulang.” (Twitter@fadlizon diunggah pada tanggal 9 April 2020).

Kata "sampah" dalam KBBI memiliki arti barang atau benda yang dibuang karena tidak terpakai lagi. Dalam komentar tersebut maksudnya adalah netizen menyamakan Fadli Zon seperti sampah, namun sampah yang tidak bisa didaur ulang atau bisa dikatakan sebagai manusia yang tidak ada gunanya. 


\section{Data 23}

@ray_Peumma “Bacottt Emberrrr..." (Twitter @fadlizon diunggah pada tanggal 31 Maret 2020).

Penanda sarkasme ilokusi pada kolom komentar akun twitter@fadlizon ini dapat ditemukan kata "bacot ember". "Bacot" dalam KBBI memiliki arti mulut, "ember" dalam KBBI memiliki arti berbentuk silikder (terbuat dari plastik, dan seng) dipakai untuk menimba air. Dapat disimpulkan dari komentar tersebut bahwa netizen menyamakan @fadlizon dengan ember maksudnya omongannya saja yang besar tanpa adanya bukti.

\section{Data 24}

@Jono_Fortunate "Bangsat Zonk.” (Twitter: @FadliZon diunggah pada tanggal 23 Februari 2020).

Penanda sarkasme ilokusi pada kolom komentar akun twitter @fadlizon ini dapat ditemukan kata “Bangsat Zonk". ”Bangsat"dalam KBBI memiliki arti gembel, miskin. Dalam komentar tersebut netizen menyamakan Fadli Zon seperti bangsat maksudnya gembel, miskin.

Penelitian gaya bahasa sarkasme pada kolom komentar akun media sosial twitter terdapat 4 jenis sarkasme yaitu sarkasme sebutan, sarkasme leksikal, sarkasme sifat dan sarkasme ilokusi. Hasil analisis dapat disimpulkan penggunaan jenis gaya bahasa sarkasme yang banyak digunakan adalah sarkasme sifat, hal ini disebabkan orang dengan mudah menilai berdasarkan apa yang mereka lihat saja kemudian mereka menyimpulkan dengan sendirinya dan hanya bisa berkomentar buruk dengan menyebutkan sifat dengan suatu hal yang kasar yang menurut mereka pas dengan sebutan untuk orang yang mereka benci, walaupun sudah berhati-hati dalam bertindak terkadang masih ada celah yang dilihat buruk oleh orang yang tidak suka kepada kita.

Dalam penelitian ini mendapatkan pengajaran baru yang dijadikan sebagai materi tambahan atau ilmu baru tentang gaya bahasa sarkasme. Pada hal ini gaya bahasa sarkasme sering digunakan oleh masyarakat dalam kehidupan sehari-hari. Tanpa 
disadari penggunaan gaya bahasa sarkasme digunakan secara terus menerus akan berakibat buruk dalam perkembangan bahasa kita serta dapat mengganggu hubungan sosial antar masyarakat yang timbul dari penggunaan gaya bahasa sarkasme tersebut yaitu akan munculnya rasa tersinggung dan sakit hati.

\section{Implikasi terhadap Pembelajaraan Bahasa Indonesia di SMA}

Implikasi pembelajaran sarkasme dalam kolom komentar akun media sosial twitter pada mata pelajaran Bahasa Indonesia di SMA khususnya kelas $\mathrm{X}$ terdapat pembelajaran mengenai gaya bahasa pada KD 3.12 Menghubungkan permasalahan isu, sudut pandang dan argumen beberapa pihak dan simpulan dari debat untuk menemukan esensi dari debat dan $\mathrm{KD}$ penerapannya yaitu 4.12 Mengkonstruksi permasalahan isu, sudut pandang dan argumen beberapa pihak esensi dari debat. Kegiatan belajar ini menyangkut peran peserta didik dalam menanggapi, menerima informasi yang terdapat dalam debat mengandung tuturan yang mempunyai makna langsung maupun tidak langsung.

Sarkasme dalam pembelajaran dimaksudkan agar peserta didik mampu mengetahui tentang sarkasme dan dapat dijadikan contoh bahwa kata-kata kasar tidak baik digunakan karena akan menyakiti hati orang lain dan akan merusak kaidah bahasa untuk masa yang akan datang jika dilakukan secara terus-menerus, maka dari itu pentingnya pendidik memberikan pembelajaran sarkasme mulai dari usia muda. Peserta didik diminta utuk mendiskusikan hasil kerja tugas yang terdapat pada buku siswa. Berdasarkan hasil kerjanya peserta didik diajak untuk mendiskusikan tentang esensi dari debat. Peserta didik diminta untuk mendiskusikan tata cara berdebat yang baik, bertukar informasi antara satu dengan yang lainnya sehingga kelompok lain dapat menanggapi dan memperoleh informasi baru. Menyampaikan hasil diskusi berupa simpulan berdasarkan hasil analisis secara lisan maupun tulis dengan menerapkan sikap jujur, teliti dan toleransi. Setelah mengikuti poses pembelajaran ini siswa dapat menemukan esensi debat, memahami 
unsur-unsur debat, memahami tata cara debat, memahami pendapat orang lain, dan menyampaikan argumen.

\section{PENUTUP}

Penelitian ini merupakan analisis wujud sarkasme berupa kata dan kalimat yang terdapat dalam kolom komentar akun media sosial twitter. Berdasarkan hasil penelitian sarkasme dalam kolom komentar akun media sosial twitter dan implikasinya terhadap pembelajaran Bahasa Indonesia di SMA diperoleh simpulan sebagai berikut. Wujud sarkasme pada media sosial twitter. Terdapat 4 jenis sarkasme yaitu sarkasme sebutan, sarkasme leksikal, sarkasme sifat dan sarkasme ilokusi. Berdasarkan hasil tersebut menunjukan 24 data pada kolom komentar akun media sosial twitter tersebut. Hasil penelitian ini diimplikasikan pada pembelajaran Bahasa Indonesia di SMA kelas X SMA semester II kurikulim 2013 KD 3.12 Menghubungkan permasalahan isu sudut pandang dan argumen beberapa pihak dan simpulan dari debat untuk menemukan esensi dari debat dan KD penerapannya yaitu 4.12 Mengkonstruksi permasalahan isu, sudut pandang dan argumen beberapa pihak esensi dari debat.

\section{DAFTAR PUSTAKA}

Arikunto, S. (2013). Prosedur Penelitian Suatu Pendekatan Praktik. Jakarta : Rineka Cipta.

Dinari, I. (2015). Jenis-jenis dan Penanda Majas Sarkasme dalam Novel The Return Of Sherlock Holmes. In Seminar Nasonal Prasasti II Kajian Pragmatik dalam Berbagai Bidang.

Hermaji, B. (2016). Teori dan Metode Sosiolinguistik. Yogyakarta : Magnum Pustaka Utama.

. (2016). Teori Pragmatik. Yogyakarta : Magnum Pustaka Utama. 
Heru, A. (2018). Gaya Bahasa Sindiran Ironi, Sinisme dan Sarkasme dalam Berita Utama Kompas. Pembahsi (Pembelajaran Bahasa Dan Sastra Indonesia), 8(2).

Keraf, G. (2009). Diksi dan Gaya Bahasa. Jakarta: PT Gramedia Pustaka Utama.

Kesuma, T. M. J. (2007). Pengantar Metode Penelitian Bahasa. Yogyakarta: Carasvalibooks.

Mahmudah. (2012). Sarkasme Judul Berita Surat Kabar Nasional. Retorika, 8(2).

Mahsun. (2007). Metode Penelitian Bahasa. Jakarta: PT Raja Grafindo.

Setiawan, M. E. (2018). “Penggunaan Gaya Bahasa Sarkasme Pada Komunitas Motor”. Diunduh 07 Januari 2020.

Tarigan, H. G. (2013). Pengajaran Gaya Bahasa. Bandung : Angkasa. 